Published in final edited form as:

Immunol Res. 2011 April ; 49(0): 124-134. doi:10.1007/s12026-010-8176-8.

\title{
The Role of Natural Regulatory T cells in Infection
}

\author{
Ana M Sanchez ${ }^{a}$ and Yiping Yang ${ }^{a, b}$ \\ aDepartment of Immunology, Duke University Medical Center, Durham, NC 27710 \\ ${ }^{b}$ Department of Medicine, Duke University Medical Center, Durham, NC 27710
}

\begin{abstract}
Naturally occurring regulatory $\mathrm{T}$ cells $\left(\mathrm{T}_{\mathrm{Reg}}\right)$ suppress multiple cell types of the immune system to maintain dominant tolerance to protect from autoimmunity, down-modulate anti-tumor immunity and restrain allergic diseases. In addition to these functions, $\mathrm{T}_{\mathrm{Reg}}$ can alter effector responses to invading pathogens, leading to a variety of outcomes affecting both the host and infecting microorganisms. Here, we review how $\mathrm{T}_{\text {Reg }}$ can influence the immune responses to chronic infections where pathogen-specific $\mathrm{T}_{\text {Reg }}$ can contribute to pathogen persistence and, in some cases, concomitant immunity, as well as control immunopathology associated with robust immune responses. We also review the data on $\mathrm{T}_{\mathrm{Reg}}$ during acute infection, focusing on the questions these studies raise regarding the most appropriate model(s) to examine $T_{\text {Reg }}$ during infection. Finally, we discuss ways in which the $\mathrm{T}_{\text {Reg }}$ function can be altered by invading pathogens and how these can be exploited to develop methods therapeutically to influence disease and vaccine outcomes.
\end{abstract}

\section{Keywords}

Regulatory T cells; infection; immunopathology; Foxp3

\section{Natural regulatory $\mathrm{T}$ cells}

More that 100 years ago, Paul Ehrlich speculated that the immune system has the potential for "horror autotoxicus" and that mechanisms must exist to avoid this deleterious fate [1]. We now know that lymphocytes of the adaptive immune system have the unique ability to discriminate between foreign and self-antigens to successfully defend against pathogens while maintaining self-tolerance. The delicate balance between autoimmunity and pathogen defense is maintained by several processes that act in both cell-intrinsic and cell-extrinsic manners. Central tolerance ensures that self-reactive $\mathrm{T}$ cells are deleted in the thymus in response to a high-affinity major histocompatability complex (MHC)/self-peptide and T-cell receptor (TCR) interaction [2]. Despite this process, a small number of self-reactive T cells enter the periphery and are controlled by three main mechanisms: deletion, induction of anergy and suppression [3]. Regulatory $\mathrm{T}$ cells $\left(\mathrm{T}_{\mathrm{Reg}}\right)$ are devoted to the active suppression of the immune system to maintain self-tolerance and immune homeostasis. For the purpose of this review, we will be focusing on naturally occurring $\mathrm{CD} 4{ }^{+} \mathrm{CD} 25^{+} \mathrm{T}_{\mathrm{Reg}}$ that develop in the thymus as a unique lineage of $\mathrm{CD} 4^{+} \mathrm{T}$ cells (for a review of induced $\mathrm{T}_{\text {Reg }}$ see [4]).

$\mathrm{T}_{\text {Reg }}$ develop in the thymus as a subset of $\mathrm{CD}^{+} \mathrm{T}$ cells that acquire their suppressive ability as the result of a unique microenvironment. While all of the signals required for this microenvironment are unknown, studies using TCR transgenic mice that co-express their cognate antigen have suggested that $\mathrm{T}_{\text {Reg }}$ development in the thymus requires high affinity

Address correspondence to Dr. Yiping Yang, Departments of Medicine and Immunology, Duke University Medical Center, Box 103005, Durham, NC 27710. Phone: (919) 668-0932; Fax: (919) 684-9594; yang0029@ mc.duke.edu. 
TCR stimulation [5-7] and is critically dependent on B7 costimulation [8, 9]. It is believed that these and potentially other signals lead to the expression of the transcription factor forkhead box $\mathrm{p} 3$ (Foxp3), which is required for and defines the $\mathrm{T}_{\text {Reg lineage }}[10,11]$. In addition to the expression of Foxp3, $\mathrm{T}_{\mathrm{Reg}}$ are characterized by the high level expression of the IL-2 receptor a chain (CD25) [10, 12], cytotoxic T lymphocyte antigen-4 (CTLA-4) [13, 14] and glucocorticoid-induced TNFR (GITR) $[15,16]$. Because these molecules can also be found on activated non- $\mathrm{T}_{\text {Reg }}$, Foxp3 is considered the most specific marker for $\mathrm{T}_{\text {Reg }}$ in both mice $[10,11]$ and humans $[17,18]$. Once $\mathrm{T}_{\mathrm{Reg}}$ develop in the thymus, they exit into the periphery where they represent $5-10 \%$ and $2-4 \%$ of the $\mathrm{CD}^{+} \mathrm{T}$ cell population in healthy mice and humans, respectively [19].

Once $\mathrm{T}_{\mathrm{Reg}}$ exit into the periphery, they perform a variety of functions. Early studies of $\mathrm{T}_{\mathrm{Reg}}$ focused on their role in dominant tolerance- the active, trans-acting suppression of the immune system. These studies initiated when it was shown that thymectomy in neonatal mice three days after birth resulted in the development of organ-specific autoimmunity that could prevented by transferring syngeneic T cells from the spleen or thymus [20]. Further work by Sakaguchi et al. demonstrated that the cell type responsible for preventing autoimmune disease in this model was $\mathrm{CD} 4^{+} \mathrm{CD} 25^{+} \mathrm{T}_{\mathrm{Reg}}[10,12]$. Later studies further classified these cells as Foxp3 $3^{+}[10,11,21]$.

The importance of $T_{\text {Reg }}$ for the maintenance of tolerance is exemplified in studies where genetic mutations or other manipulations that functionally delete $T_{\text {Reg }}$ results in aggressive and fatal autoimmune disease. Mice with the spontaneous scurfy mutation ( $s f$ ), which renders Foxp3 nonfunctional, develop fatal autoimmune disease characterized by severe lymphoproliferative and lymphocytic organ-infiltration ultimately leading to death three to four weeks after birth [22, 23]. In humans, an analogous mutation leads to a condition termed 'immune dysregulation, polyendocrinopathy, enteropathy, X-linked' (IPEX), where patients display symptoms similar to those seen in $s f$ mice [24-26]. Disregulation of $\mathrm{T}_{\mathrm{Reg}}$ has also been associated with other autoimmune diseases including multiple sclerosis, type 1 diabetes and rheumatoid arthritis [27-29]. In addition to autoimmune diseases, $\mathrm{T}_{\mathrm{Reg}}$ have been implicated in the development of allergic diseases such as asthma [30], in the suppression of anti-tumor immunity [31] and during pathogen infection, which will be discussed at length here.

The diverse functions of $\mathrm{T}_{\mathrm{Reg}}$ are a result of their ability to suppress multiple cells of the immune system, including non- $\mathrm{T}_{\text {Reg }} \mathrm{CD} 4^{+} \mathrm{T}$ cells, $\mathrm{CD} 8^{+} \mathrm{T}$ cells, dendritic cells (DC), B cells, natural killer (NK) cells, NK T cells, macrophage and mast cells [8, 32-38]. Currently, the exact mechanisms by which $\mathrm{T}_{\text {Reg }}$ suppress all these cell types are not fully elucidated, and many mechanisms remain controversial. Current evidence suggests that in vivo suppression can be mediated by anti-inflammatory cytokines, such as interleukin 10 (IL-10), IL-35 and transforming growth factor $\beta$ (TGF- $\beta$ ) and via cell-cell contact potentially through the inhibitory receptor CTLA-4 $[39,40]$. Additional studies have suggested a role for granzyme or perforin-dependent killing [41-43] and adenosine and cyclic AMP in $T_{\text {Reg }}$ suppression [44, 45]. Studies using intravital two-photon laser scanning microscopy (TPLSM) have attempted to further understand the dynamics of $\mathrm{T}_{\text {Reg }}$ suppression in vivo. These studies have demonstrated that $\mathrm{T}_{\text {Reg }}$ suppress the immune response by preventing stable contact between DCs and non- $\mathrm{T}_{\mathrm{Reg}}[46,47]$ suggesting that in vivo $\mathrm{T}_{\mathrm{Reg}}$ may modulate antigen presenting cells (APC) function to suppress T cells. Further studies are required to more fully appreciate how suppression occurs in vivo and what mechanisms of suppression are utilized during pathogen invasion. 


\section{Regulatory $\mathrm{T}$ cells in chronic infection}

While initial studies with $T_{\text {Reg }}$ focused on their role in dominant tolerance, accumulating evidence indicates an important role for $\mathrm{T}_{\text {Reg }}$ in the control of immune responses to pathogens $[48,49]$. One of the earliest implications for this role came from a model of chronic infection with Leishmania major when it was demonstrated that IL-10, which is known to be produced by $\mathrm{T}_{\mathrm{Reg}}$, contributes to pathogen persistence [50]. Subsequent studies demonstrated that Leishmania-specific $\mathrm{T}_{\mathrm{Reg}}$ found at the sites of infection suppress $\mathrm{T}$ cells, by both IL-10-dependent and -independent mechanisms, to prevent complete pathogen clearance, leading to the development of concomitant immunity [51, 52]. Additional studies in both experimental animal models and humans have shown that $\mathrm{T}_{\text {Reg }}$ can accumulate following multiple types of infections and modulate the immune response in a variety of ways that can be beneficial for both the host and the pathogen.

Studies in humans have demonstrated that $\mathrm{T}_{\text {Reg }}$ can expand following infection and accumulate at the sites of infection. For example, $\mathrm{T}_{\mathrm{Reg}}$ have been found in patients with parasitic infections (i.e. Leishmania braziliensis [53]), viral infections (i.e. hepatitis B [54]), fungal infection (i.e. Paracoccidioides brasiliensis [55]) and bacterial infection (i.e. Helicobacter pylori [56]). Studies to examine the effect of $\mathrm{T}_{\mathrm{Reg}}$ during human infection are generally limited to an in vitro suppression assay whereby responder cells (non- $\mathrm{T}_{\mathrm{Reg}}$ ) are cultured with $\mathrm{T}_{\mathrm{Reg}}$ in the presence of a stimulus for activation (i.e. APC + anti-CD3 antibody or agonist peptide). When these cells are cultured together, $\mathrm{T}_{\mathrm{Reg}}$ will suppress the proliferation of non- $\mathrm{T}_{\mathrm{Reg}}$, which can be experimentally measured. Using this method, the suppression of pathogen-specific effector cells by human $T_{\text {Reg }}$ has been demonstrated in a variety of disease models including Plasmodium falciparum where the removal of $\mathrm{T}_{\mathrm{Reg}}$ enhances in vitro immune responses against the pathogen [57]. While in vivo evidence for $\mathrm{T}_{\text {Reg }}$ function during infection in humans is lacking, one study comparing an ethnic group with a naturally lower susceptibility to Plasmodium falciparum malaria than sympatric ethnic groups has shed some light. It was found that the group's resistance was not associated with classic malaria-resistance genes, but rather may be related to the fact that members of this group have a propensity for functionally deficient $\mathrm{T}_{\text {Reg }}$ characterized by reduced RNA for genes associated with $\mathrm{T}_{\text {Reg }}$ function, as well as lower serum levels of TGF- $\beta$ [57]. These data suggest a strong role for $\mathrm{T}_{\mathrm{Reg}}$ in malaria resistance and provide a unique human system to further understand how $\mathrm{T}_{\mathrm{Reg}}$ can affect the outcome of pathogen infection.

To more fully understand the role of $\mathrm{T}_{\mathrm{Reg}}$ during infection than can be garnered with human studies, murine models of chronic parasitic, bacterial, viral and fungal infections have been utilized. These experiment have shown that the presence of $T_{\text {Reg }}$ can suppress effector cells, preventing the immune system from mounting an effective immune response, which can lead to pathogen persistence. In some extreme cases, this can be detrimental to host survival, such as infection with a lethal strain of Plasmodium yoelii where $\mathrm{T}_{\text {Reg }}$ vigorously block an effective immune response, and depletion of $\mathrm{T}_{\text {Reg }}$ can actually improve host survival [58]. In what appears to be a similar mechanism, during infection with a hypervirulent, lethal strain of Mycobacterium tuberculosis as the infection proceeds, the number of effector $\mathrm{T}$ cells is reduced, and this is associated with an increase in the presence of $\mathrm{T}_{\text {Reg }}$ [59]. Further studies are required to confirm that the $\mathrm{T}_{\mathrm{Reg}}$ are responsible for the decrease in effector cells and whether this is related to the lethality of this strain.

Multiple other studies of chronic infection have demonstrated that, while the presence of $\mathrm{T}_{\text {Reg }}$ does not contribute to the pathogen's lethality, depletion of $\mathrm{T}_{\text {Reg }}$ leads to increased effector responses, supporting pathogen clearance. For example, in a murine model of ocular infection with herpes simplex virus 1 (HSV1), depletion of $\mathrm{T}_{\text {Reg }}$ leads to enhanced CD4 and 
CD8 expansion, effector function and infiltration into the cornea [60, 61]. Similar enhancement of effector function has been observed in multiple other models of parasitic, bacterial, fungal and viral infection (for review see [62]). However, not all studies have demonstrated that $\mathrm{T}_{\mathrm{Reg}}$ function to block effector activation. With Mycobacterium tuberculosis (Mtb) infection, depletion of Foxp $3^{+} \mathrm{T}_{\mathrm{Reg}}$ prior to infection results in significantly reduced bacterial burden in the lungs, but this reduction was not associated with an increase in pathogen-specific non- $\mathrm{T}_{\text {Reg }}$ effector function. This seemingly paradoxical effect may be related to the low levels of antigen available for $\mathrm{T}$ cell activation that occurs following $T_{\text {Reg }}$ depletion in this model [63]. However, using the same model of infection, Quinn et al. demonstrated that depleting $\mathrm{T}_{\text {Reg }}$ with an anti-CD25 antibody increased effector IFN- $\gamma$, production but did not alter bacterial load [64] suggesting that the effects observed during $\mathrm{T}_{\text {Reg }}$ depletion may be related to the method of depletion utilized, which may be critical in this particular model because pathogen load is highly limiting to $\mathrm{T}$ cell expansion due to the inefficiency of antigen presentation.

While the presence of $T_{\text {Reg }}$ may lead to pathogen persistence, this can actually be beneficial for the host as it is becoming increasingly clear that this can be critical to develop protective immunity. For example, with L. major infection the downregulation of the effector response by $\mathrm{T}_{\text {Reg }}$ leads to concomitant immunity, which is lost by removal of $\mathrm{T}_{\text {Reg }}$ [52]. This has also been demonstrated with a murine model of infection with the fungus Candida albicans where the presence of $\mathrm{T}_{\mathrm{Reg}}$ was required for resistance to reinfection [65]. Additionally, similar results have been observed in infection with a lose-dose of HSV1 [60].

In addition to allowing for the development of protective immunity, $\mathrm{T}_{\mathrm{Reg}}$ can benefit the host by reducing immune-mediated pathology that can occur as collateral damage associated with a strong anti-pathogen immune response. This role for $\mathrm{T}_{\mathrm{Reg}}$ in protecting against immune-mediated damage has been demonstrated in models of pulmonary inflammation caused by Pneumocystis pneumonia, inflammatory eye lesions with HSV, liver pathology in Schistosoma mansoni infection and stomach pathology with Candida albicans where depletion of $\mathrm{T}_{\text {Reg }}$ leads to enhanced pathology [60, 65-68]. However, not all chronic models of infection support a role for $\mathrm{T}_{\mathrm{Reg}}$ in the prevention of immunopathology. Paradoxically, in a model of Plasmodium yoelii infection, removal of $\mathrm{T}_{\text {Reg }}$ actually resulted in reduced immunopathology in the brain [69]. This result was thought to occur because the depletion of $\mathrm{T}_{\text {Reg }}$ significantly reduced both parasite burden and the recruitment of $\mathrm{CD} 8^{+} \mathrm{T}$ cells in the brain [69]. In this model of experimental cerebral malaria (ECM) it appears as if the high parasite burden localized in the brain, as well as the potential exclusion of $\mathrm{T}_{\mathrm{Reg}}$ from the brain during ECM [70], may make immunopathology an unavoidable consequence to combating $P$. yoelii infection.

Collectively, these results indicate there is a delicate balance between $T_{\text {Reg }}$ and non- $T_{\text {Reg }}$, and any changes to this equilibrium can alter the outcome of a chronic infection. If $\mathrm{T}_{\mathrm{Reg}}$ suppression is too vigorous, this can lead to poor pathogen clearance and possibly even host death. On the other end of the spectrum, without adequate suppression, non- $\mathrm{T}_{\mathrm{Reg}}$ can cause collateral tissue damage due to an overzealous immune response. However, if non- $\mathrm{T}_{\mathrm{Reg}}$ and $\mathrm{T}_{\mathrm{Reg}}$ are balanced then this can lead to protective immunity without excessive immunopathology. Studies are underway to determine whether this balance can be exploited to modulate vaccine or disease outcomes.

\section{Regulatory $T$ cells in acute infection}

Compared to studies with chronic infection, to date very few studies have been conducted to understand the function of $\mathrm{T}_{\text {Reg }}$ during acute infection. The results of these studies have painted contradictory roles for $\mathrm{T}_{\mathrm{Reg}}$ during acute infection and highlight how different 
models of $\mathrm{T}_{\text {Reg }}$ depletion can lead to opposing results. Utilizing an anti-CD25 antibody to deplete $\mathrm{T}_{\mathrm{Reg}}$, it was shown that $\mathrm{T}_{\text {Reg }}$ do not affect the immune response or the disease outcome in Pseudomonas aeruginosa lung infection in mice [71]. Using a similar method of depletion, two independent studies examined $\mathrm{T}_{\mathrm{Reg}}$ during acute Trypanosoma cruzi infection in mice and found no role in one of the studies and a limited role for $\mathrm{T}_{\mathrm{Reg}}$ in the other study $[72,73]$. The impact of $\mathrm{T}_{\mathrm{Reg}}$ was largely dependent on the dose of $T$. cruzi where mice receiving a lower dose displayed reduced parasitemia and mortality following $\mathrm{T}_{\mathrm{Reg}}$ depletion, but these effects were no longer observed when higher numbers of parasites were used for infection [73]. The discrepancies between these two studies and between the different parasite doses may be related to the relative inefficiency of $\mathrm{T}_{\text {Reg }}$ depletion by antiCD25 antibodies observed during infection and/or the depletion of effector T cells, which upregulate CD25 following activation $[74,75]$. These pitfalls of depletion may be more apparent in models of acute infection because effector cells can express higher levels of CD25 during acute compared to chronic infection [75]. Because of these caveats with CD25 antibody depletion, newer mouse models that selectively deplete Foxp $3^{+} \mathrm{T}_{\text {Reg }}$ may provide a better method to study the role of $\mathrm{T}_{\text {Reg }}$ during infection.

To overcome the inherent problems of using anti-CD25 antibodies to study $\mathrm{T}_{\mathrm{Reg}}$ during infection, Foxp $3^{D T R}$ mice, which express the human diphtheria toxin receptor (DTR) under control of the Foxp3 promoter, have been used to study $\mathrm{T}_{\text {Reg }}$ during acute genital infection with HSV-2 [76]. In these mice, treatment with DT allows for the rapid and efficient depletion of Foxp3-expressing cells [77]. The results from these experiments were quite unexpected; while $\mathrm{T}_{\mathrm{Reg}}$-depleted mice displayed increased activation of effector cells in the draining lymph nodes, they were unable to control genital HSV-2 infection [76]. This led to severe lesions and faster viral dissemination into the spinal cord resulting in hindlimb paralysis, and as a result, DT-treated Foxp3 $3^{\mathrm{DTR}}$ mice succumbed to disease much earlier than $\mathrm{T}_{\mathrm{Reg}}$-sufficient mice [76]. This apparently paradoxical effect was related to $\mathrm{T}_{\mathrm{Reg}}$ modulating chemokine levels to ensure proper recruitment of immune cells to the site of infection [76]. In $\mathrm{T}_{\text {Reg }}$-depleted mice the arrival of DCs, NK cells and $\mathrm{T}$ cells was delayed at the site of infection compared to $\mathrm{T}_{\mathrm{Reg}}$-sufficient mice [76]. This is not the first report that has implicated a role for $\mathrm{T}_{\text {Reg }}$ in cellular migration; in a model of respiratory syncytial virus infection, $\mathrm{T}_{\mathrm{Reg}}$ were shown to alter $\mathrm{CD} 8^{+} \mathrm{T}$ cell trafficking to the lung following infection [78].

While using Foxp3-DTR mice is a much more specific method to study the role of $\mathrm{T}_{\mathrm{Reg}}$ during infection, they must be carefully controlled to ensure that they are properly interpreted. Depletion of $\mathrm{T}_{\text {Reg }}$ using this method leads to increased activation of $\mathrm{T}$ cells, an increase in the number and activation of DC and the production of inflammatory cytokines and chemokines even in the absence of infection [76, 77]. These effects may be a direct result of increased activation of autoreactive $\mathrm{T}$ cells, which are normally controlled by $\mathrm{T}_{\mathrm{Reg}}$, but may also reflect direct or indirect effects of $\mathrm{T}_{\mathrm{Reg}}$ on other cells of the immune system, such as NK cells or DC. These changes highlight the catastrophic changes that occur in the immune system when $T_{\text {Reg }}$ are ablated and suggest that a more fine-tuned approach may be necessary to study $\mathrm{T}_{\text {Reg }}$ function during an immune response to ensure that the effects observed are not related to induced autoimmunity.

These studies also raise the question as to whether suppression during infection is antigenspecific or whether it occurs as the result of a bystander effect of $\mathrm{T}_{\text {Reg }}$ responding to selfantigens. This is critical to determine whether depletion of the polyclonal $\mathrm{T}_{\text {Reg }}$ population is the best method to study $T_{\text {Reg }}$ during infection. Previous work to classify the $T_{\text {Reg }}$ TCR repertoire has suggested some overlap between the TCRs of $\mathrm{T}_{\text {Reg }}$ and non- $\mathrm{T}_{\text {Reg }}$ suggesting that $\mathrm{T}_{\mathrm{Reg}}$ could recognize more than just self-antigens [79, 80]. Indeed, work by Suffia et al. demonstrated that $\mathrm{T}_{\mathrm{Reg}}$ found at the sites of $L$. major infection proliferate in a pathogen- 
specific manner and that suppression in vitro is antigen-specific [51]. Additional studies with both mice and humans in other models of infection support these observations [81, 82]. While the antigen-specificity of suppression in vivo has been demonstrated in our laboratory in an autoimmune setting [83], further studies are necessary to demonstrate that the in vivo suppression observed during infection is antigen-specific. Additionally, studies to examine whether non- $\mathrm{T}_{\text {Reg }}$ and $\mathrm{T}_{\mathrm{Reg}}$ recognize the same the immunodominant epitopes as this may provide a mechanism to discriminate between the two cell types in vaccine development.

Taken together, it is clear that additional studies with acute infection are necessary as multiple additional questions remain. First, it is still not entirely clear whether $\mathrm{T}_{\text {Reg }}$ play a role during acute infection or perhaps in just select acute infection models. These questions can be addressed utilizing different models of acute infection coupled with different approaches to deplete $T_{\text {Reg }}$ perhaps identifying systems that do not remove the polyclonal population but rather study pathogen-specific $\mathrm{T}_{\mathrm{Reg}}$. Additionally, work will need to be done to further clarify how $\mathrm{T}_{\mathrm{Reg}}$ modulate the outcome acute infection, for example, whether they simply modulate migration as with genital HSV-2 infection or influence effector function and/or immunopathology as observed in chronic infection models. Finally, studies using acute infection models can be used to determine what happens to activated $\mathrm{T}_{\mathrm{Reg}}$ following the resolution of an acute infection.

\section{Manipulating regulatory $\mathrm{T}$ cells to regulate disease or vaccine outcome}

Because of the important function of $\mathrm{T}_{\text {Reg }}$ during infection, researchers are studying how to manipulate them to adjust either disease or vaccine outcome. While therapeutic modulation of $\mathrm{T}_{\mathrm{Reg}}$ is a viable research area, it appears as if microorganisms have already devised mechanisms to alter $\mathrm{T}_{\text {Reg }}$ function to promote their survival. One mechanism for modulation by pathogens may be through recognition of pathogens by innate pathogen pattern receptors such as Toll-like receptors (TLRs) (for review see [84]). While it has been demonstrated that $\mathrm{T}_{\text {Reg }}$ express various TLRs, how direct TLR signaling on $\mathrm{T}_{\text {Reg }}$ has not been fully elucidated and remains debated. Some studies have suggested that TLR2 or 8 stimulation abrogates the suppressive capacity of $\mathrm{T}_{\mathrm{Reg}}$, while others have shown that TLR4 and 5 can act to enhance suppression [84]. These studies are not without controversy, however, as it was recently suggested that TLR2 stimulation of $\mathrm{T}_{\text {Reg }}$ results in increased survival, but does not affect suppressive capacity [85]. Because many of these studies have been conducted in vitro, additional studies are necessary to fully tease apart the intricacies of TLR signaling on $T_{\text {Reg }}$ function in vivo. In addition to direct TLR stimulation on $\mathrm{T}_{\text {Reg }}$, TLRs can also affect $\mathrm{T}_{\mathrm{Reg}}$ through an indirect mechanism via DCs to block their ability to suppress via an IL-6dependent mechanism [86].

Another mechanism by which pathogens may alter $\mathrm{T}_{\mathrm{Reg}}$ is though the creation of chemokine microenvironments that support $\mathrm{T}_{\mathrm{Reg}}$ retention at the site of infection. There is evidence that chemokine receptor and integrin expression on $\mathrm{T}_{\mathrm{Reg}}$ are critical for their function [87-89]. Expression of the integrin $\alpha_{E} \beta_{7}$ (CD103), which primarily binds to E-cadherin, can be used to separate $\mathrm{T}_{\text {Reg }}$ with "effector/memory" phenotypes that have enhanced suppressive capabilities and distinct homing properties [90, 91]. Studies have demonstrated a role for $\mathrm{CD}_{103}{ }^{+} \mathrm{T}_{\text {Reg }}$ during infection. Work with $L$. major has demonstrated that CD103 is required for retention of $\mathrm{T}_{\mathrm{Reg}}$ at the sites of infection and that $L$. major-infected DC can stimulate CD103 expression in $\mathrm{T}_{\mathrm{Reg}}$ [92] suggesting that the pathogen manipulates DCs to support $\mathrm{T}_{\mathrm{Reg}}$ retention. Further work with $L$. major infection has shown that the chemokine receptor CCR5 is critical for $\mathrm{T}_{\text {Reg }}$ migration into the skin. [93]. Similar results with CCR5 have also been shown with the dimorphic fungi Paracoccidiodes brasiliensis and Histoplasma capsulatum $[94,95]$. These data suggest unique chemokine and integrin signals are utilized by $\mathrm{T}_{\mathrm{Reg}}$ to migrate to sites of infection and perhaps that the expression of these 
receptors can be modulated by pathogens. Additional work is necessary to explore other chemokines and/or integrins that affect $\mathrm{T}_{\mathrm{Reg}}$ migration during infection and the ways in which pathogens can manipulate the expression of these molecules.

By understanding the ways in which microbes modulate $T_{\text {Reg }}$, as well as the ways in which $\mathrm{T}_{\text {Reg }}$ suppress, therapies can be developed to target $\mathrm{T}_{\text {Reg }}$ to manipulate disease or vaccine outcome to control microorganisms, block immunopathology or support the development of protective memory. With any of these potential therapies, care will need to be taken to maintain the balance between immunity to pathogens and autoimmunity as ablation of $\mathrm{T}_{\text {Reg }}$ can have deleterious effects [77]. As with studies in infection, perhaps therapies aimed a pathogen-specific $\mathrm{T}_{\mathrm{Reg}}$ may be an effective and specific method that could avoid potentially damaging side effects.

\section{Concluding remarks}

Our knowledge about the functions of $\mathrm{T}_{\text {Reg }}$ in the immune system has grown tremendously since the days of the ill-fated "suppressor cell." This expanding knowledge has revealed unique roles for $\mathrm{T}_{\mathrm{Reg}}$ during pathogen invasion, especially in models of chronic infection. To further understand how $\mathrm{T}_{\text {Reg }}$ modulate infection outcomes, novel model systems of $\mathrm{T}_{\text {Reg }}$ depletion or addition will need to be carried out, particularly with acute infections. Elucidating these roles more fully, as well as the ways in which pathogens modulate $\mathrm{T}_{\mathrm{Reg}}$ function is critical to harness their potential for vaccine development or therapeutics to treat infection. Overall, research examining $\mathrm{T}_{\text {Reg }}$ during infection has suggested that the relationship between $\mathrm{T}_{\text {Reg }}$, invading microorganisms and the resulting immune response is one filled with various ententes, which will need to be considered in any therapeutic intervention.

\section{Acknowledgments}

This work was supported by the National Institutes of Health grants CA047741, CA111807, and CA136934 (to Y.Y.), an Alliance for Cancer Gene Therapy grant (to Y.Y.)

\section{References}

1. Ehrlich, P. Collected Studies on Immunity. New York: J. Wiley \& Sons; 1910.

2. Hogquist KA, Baldwin TA, Jameson SC. Central tolerance: learning self-control in the thymus. Nature reviews. 2005; 5:772-782.

3. Abbas AK, Lohr J, Knoechel B, Nagabhushanam V. T cell tolerance and autoimmunity. Autoimmun Rev. 2004; 3:471-475. [PubMed: 15546793]

4. Curotto de Lafaille MA, Lafaille JJ. Natural and adaptive foxp3+ regulatory T cells: more of the same or a division of labor? Immunity. 2009; 30:626-635. [PubMed: 19464985]

5. Kawahata K, et al. Generation of CD4(+)CD25(+) regulatory T cells from autoreactive T cells simultaneously with their negative selection in the thymus and from nonautoreactive $\mathrm{T}$ cells by endogenous TCR expression. J Immunol. 2002; 168:4399-4405. [PubMed: 11970982]

6. Apostolou I, Sarukhan A, Klein L, von Boehmer H. Origin of regulatory T cells with known specificity for antigen. Nature immunology. 2002; 3:756-763. [PubMed: 12089509]

7. Jordan MS, et al. Thymic selection of CD4+CD25+ regulatory T cells induced by an agonist selfpeptide. Nature immunology. 2001; 2:301-306. [PubMed: 11276200]

8. Ghiringhelli F, et al. CD4+CD25+ regulatory T cells inhibit natural killer cell functions in a transforming growth factor-beta-dependent manner. The Journal of experimental medicine. 2005; 202:1075-1085. [PubMed: 16230475]

9. Tang Q, et al. Cutting edge: CD28 controls peripheral homeostasis of CD4+CD25+ regulatory T cells. J Immunol. 2003; 171:3348-3352. [PubMed: 14500627] 
10. Hori S, Nomura T, Sakaguchi S. Control of regulatory T cell development by the transcription factor Foxp3. Science (New York, NY. 2003; 299:1057-1061.

11. Fontenot JD, Gavin MA, Rudensky AY. Foxp3 programs the development and function of CD4+CD25+ regulatory T cells. Nature immunology. 2003; 4:330-336. [PubMed: 12612578]

12. Sakaguchi S, Sakaguchi N, Asano M, Itoh M, Toda M. Immunologic self-tolerance maintained by activated T cells expressing IL-2 receptor alpha-chains (CD25). Breakdown of a single mechanism of self-tolerance causes various autoimmune diseases. J Immunol. 1995; 155:1151-1164. [PubMed: 7636184]

13. Read S, Malmstrom V, Powrie F. Cytotoxic T lymphocyte-associated antigen 4 plays an essential role in the function of $\mathrm{CD} 25(+) \mathrm{CD} 4(+)$ regulatory cells that control intestinal inflammation. The Journal of experimental medicine. 2000; 192:295-302. [PubMed: 10899916]

14. Takahashi $\mathrm{T}$, et al. Immunologic self-tolerance maintained by CD25(+)CD4(+) regulatory $\mathrm{T}$ cells constitutively expressing cytotoxic T lymphocyte-associated antigen 4 . The Journal of experimental medicine. 2000; 192:303-310. [PubMed: 10899917]

15. McHugh RS, et al. CD4(+)CD25(+) immunoregulatory T cells: gene expression analysis reveals a functional role for the glucocorticoid-induced TNF receptor. Immunity. 2002; 16:311-323. [PubMed: 11869690]

16. Shimizu J, Yamazaki S, Takahashi T, Ishida Y, Sakaguchi S. Stimulation of CD25(+)CD4(+) regulatory T cells through GITR breaks immunological self-tolerance. Nature immunology. 2002; 3:135-142. [PubMed: 11812990]

17. Walker MR, et al. Induction of FoxP3 and acquisition of T regulatory activity by stimulated human CD4+CD25- T cells. The Journal of clinical investigation. 2003; 112:1437-1443. [PubMed: 14597769]

18. Wang HY, et al. Tumor-specific human CD4+ regulatory T cells and their ligands: implications for immunotherapy. Immunity. 2004; 20:107-118. [PubMed: 14738769]

19. Baecher-Allan C, Viglietta V, Hafler DA. Human CD4+CD25+ regulatory T cells. Seminars in immunology. 2004; 16:89-98. [PubMed: 15036232]

20. Nishizuka Y, Sakakura T. Thymus and reproduction: sex-linked dysgenesia of the gonad after neonatal thymectomy in mice. Science (New York, NY. 1969; 166:753-755.

21. Khattri R, Cox T, Yasayko SA, Ramsdell F. An essential role for Scurfin in CD4+CD25+ T regulatory cells. Nature immunology. 2003; 4:337-342. [PubMed: 12612581]

22. Godfrey VL, Wilkinson JE, Russell LB. X-linked lymphoreticular disease in the scurfy (sf) mutant mouse. The American journal of pathology. 1991; 138:1379-1387. [PubMed: 2053595]

23. Brunkow ME, et al. Disruption of a new forkhead/winged-helix protein, scurfin, results in the fatal lymphoproliferative disorder of the scurfy mouse. Nat Genet. 2001; 27:68-73. [PubMed: 11138001]

24. Bennett CL, et al. The immune dysregulation, polyendocrinopathy, enteropathy, X-linked syndrome (IPEX) is caused by mutations of FOXP3. Nat Genet. 2001; 27:20-21. [PubMed: 11137993]

25. Chatila TA, et al. JM2, encoding a fork head-related protein, is mutated in X-linked autoimmunityallergic disregulation syndrome. The Journal of clinical investigation. 2000; 106:R75-R81. [PubMed: 11120765]

26. Wildin RS, et al. X-linked neonatal diabetes mellitus, enteropathy and endocrinopathy syndrome is the human equivalent of mouse scurfy. Nat Genet. 2001; 27:18-20. [PubMed: 11137992]

27. Viglietta V, Baecher-Allan C, Weiner HL, Hafler DA. Loss of functional suppression by CD4+CD25+ regulatory $\mathrm{T}$ cells in patients with multiple sclerosis. The Journal of experimental medicine. 2004; 199:971-979. [PubMed: 15067033]

28. Lindley S, Dayan CM, Bishop A, Roep BO, Peakman M, Tree TI. Defective suppressor function in CD4(+)CD25(+) T-cells from patients with type 1 diabetes. Diabetes. 2005; 54:92-99. [PubMed: 15616015]

29. Ehrenstein MR, et al. Compromised function of regulatory $T$ cells in rheumatoid arthritis and reversal by anti-TNFalpha therapy. The Journal of experimental medicine. 2004; 200:277-285. [PubMed: 15280421] 
30. Curotto de Lafaille MA, Lafaille JJ. CD4(+) regulatory T cells in autoimmunity and allergy. Current opinion in immunology. 2002; 14:771-778. [PubMed: 12413528]

31. Wang HY, Wang RF. Regulatory T cells and cancer. Current opinion in immunology. 2007; 19:217-223. [PubMed: 17306521]

32. von Boehmer H. Mechanisms of suppression by suppressor T cells. Nature immunology. 2005; 6:338-344. [PubMed: 15785759]

33. Piccirillo CA, Shevach EM. Cutting edge: control of CD8+ T cell activation by CD4+CD25+ immunoregulatory cells. J Immunol. 2001; 167:1137-1140. [PubMed: 11466326]

34. Misra N, Bayry J, Lacroix-Desmazes S, Kazatchkine MD, Kaveri SV. Cutting edge: human $\mathrm{CD} 4+\mathrm{CD} 25+\mathrm{T}$ cells restrain the maturation and antigen-presenting function of dendritic cells. J Immunol. 2004; 172:4676-4680. [PubMed: 15067041]

35. Lim HW, Hillsamer P, Banham AH, Kim CH. Cutting edge: direct suppression of B cells by CD4+ CD25+ regulatory T cells. J Immunol. 2005; 175:4180-4183. [PubMed: 16177055]

36. La Cava A, Van Kaer L, Fu Dong S. CD4+CD25+ Tregs and NKT cells: regulators regulating regulators. Trends Immunol. 2006; 27:322-327. [PubMed: 16735139]

37. Taams LS, et al. Modulation of monocyte/macrophage function by human CD4+CD25+ regulatory T cells. Hum Immunol. 2005; 66:222-230. [PubMed: 15784460]

38. Gri G, et al. CD4+CD25+ regulatory T cells suppress mast cell degranulation and allergic responses through OX40-OX40L interaction. Immunity. 2008; 29:771-781. [PubMed: 18993084]

39. Miyara M, Sakaguchi S. Natural regulatory T cells: mechanisms of suppression. Trends in molecular medicine. 2007; 13:108-116. [PubMed: 17257897]

40. Rudensky AY, Campbell DJ. In vivo sites and cellular mechanisms of T reg cell-mediated suppression. The Journal of experimental medicine. 2006; 203:489-492. [PubMed: 16533888]

41. Grossman WJ, Verbsky JW, Barchet W, Colonna M, Atkinson JP, Ley TJ. Human T regulatory cells can use the perforin pathway to cause autologous target cell death. Immunity. 2004; 21:589601. [PubMed: 15485635]

42. Gondek DC, Lu LF, Quezada SA, Sakaguchi S, Noelle RJ. Cutting edge: contact-mediated suppression by $\mathrm{CD} 4+\mathrm{CD} 25+$ regulatory cells involves a granzyme B-dependent, perforinindependent mechanism. J Immunol. 2005; 174:1783-1786. [PubMed: 15699103]

43. Cao X, et al. Granzyme B and perforin are important for regulatory T cell-mediated suppression of tumor clearance. Immunity. 2007; 27:635-646. [PubMed: 17919943]

44. Bopp T, et al. Cyclic adenosine monophosphate is a key component of regulatory T cell-mediated suppression. The Journal of experimental medicine. 2007; 204:1303-1310. [PubMed: 17502663]

45. Deaglio S, et al. Adenosine generation catalyzed by CD39 and CD73 expressed on regulatory T cells mediates immune suppression. The Journal of experimental medicine. 2007; 204:1257-1265. [PubMed: 17502665]

46. Tadokoro CE, et al. Regulatory $\mathrm{T}$ cells inhibit stable contacts between CD4+ T cells and dendritic cells in vivo. The Journal of experimental medicine. 2006; 203:505-511. [PubMed: 16533880]

47. Tang Q, et al. Visualizing regulatory $\mathrm{T}$ cell control of autoimmune responses in nonobese diabetic mice. Nature immunology. 2006; 7:83-92. [PubMed: 16311599]

48. Mills KH. Regulatory T cells: friend or foe in immunity to infection? Nat Rev Immunol. 2004; 4:841-855. [PubMed: 15516964]

49. Belkaid Y, Rouse BT. Natural regulatory T cells in infectious disease. Nat Immunol. 2005; 6:353360. [PubMed: 15785761]

50. Belkaid Y, et al. The role of interleukin (IL)-10 in the persistence of Leishmania major in the skin after healing and the therapeutic potential of anti-IL-10 receptor antibody for sterile cure. The Journal of experimental medicine. 2001; 194:1497-506. [PubMed: 11714756]

51. Suffia IJ, Reckling SK, Piccirillo CA, Goldszmid RS, Belkaid Y. Infected site-restricted Foxp3+ natural regulatory $\mathrm{T}$ cells are specific for microbial antigens. The Journal of experimental medicine. 2006; 203:777-788. [PubMed: 16533885]

52. Belkaid Y, Piccirillo CA, Mendez S, Shevach EM, Sacks DL. CD4+CD25+ regulatory T cells control Leishmania major persistence and immunity. Nature. 2002; 420:502-507. [PubMed: 12466842] 
53. Campanelli AP, et al. CD4+CD25+ T cells in skin lesions of patients with cutaneous leishmaniasis exhibit phenotypic and functional characteristics of natural regulatory T cells. J Infect Dis. 2006; 193:1313-1322. [PubMed: 16586370]

54. Xu D, et al. Circulating and liver resident CD4+CD25+ regulatory $\mathrm{T}$ cells actively influence the antiviral immune response and disease progression in patients with hepatitis B. J Immunol. 2006; 177:739-747. [PubMed: 16785573]

55. Cavassani KA, et al. Systemic and local characterization of regulatory $\mathrm{T}$ cells in a chronic fungal infection in humans. J Immunol. 2006; 177:5811-5818. [PubMed: 17056505]

56. Kandulski A, et al. Naturally occurring regulatory T cells (CD4+, CD25high, FOXP3+) in the antrum and cardia are associated with higher $\mathrm{H}$. pylori colonization and increased gene expression of TGF-beta1. Helicobacter. 2008; 13:295-303. [PubMed: 18665940]

57. Walther M, et al. Upregulation of TGF-beta, FOXP3, and CD4+CD25+ regulatory T cells correlates with more rapid parasite growth in human malaria infection. Immunity. 2005; 23:287296. [PubMed: 16169501]

58. Hisaeda $\mathrm{H}$, et al. Escape of malaria parasites from host immunity requires CD4+ CD25+ regulatory T cells. Nat Med. 2004; 10:29-30. [PubMed: 14702631]

59. Ordway D, et al. The hypervirulent Mycobacterium tuberculosis strain HN878 induces a potent TH1 response followed by rapid down-regulation. J Immunol. 2007; 179:522-531. [PubMed: 17579073]

60. Suvas S, Azkur AK, Kim BS, Kumaraguru U, Rouse BT. CD4+CD25+ regulatory T cells control the severity of viral immunoinflammatory lesions. J Immunol. 2004; 172:4123-4132. [PubMed: 15034024]

61. Suvas S, Kumaraguru U, Pack CD, Lee S, Rouse BT. CD4+CD25+ T cells regulate virus-specific primary and memory CD8+ T cell responses. The Journal of experimental medicine. 2003; 198:889-901. [PubMed: 12975455]

62. Belkaid Y, Tarbell K. Regulatory T cells in the control of host-microorganism interactions (*). Annual review of immunology. 2009; 27:551-589.

63. Scott-Browne JP, et al. Expansion and function of Foxp3-expressing T regulatory cells during tuberculosis. The Journal of experimental medicine. 2007; 204:2159-2169. [PubMed: 17709423]

64. Quinn KM, et al. Inactivation of CD4+ CD25+ regulatory T cells during early mycobacterial infection increases cytokine production but does not affect pathogen load. Immunol Cell Biol. 2006; 84:467-474. [PubMed: 16869940]

65. Montagnoli C, et al. B7/CD28-dependent CD4+CD25+ regulatory T cells are essential components of the memory-protective immunity to Candida albicans. J Immunol. 2002; 169:6298-6308. [PubMed: 12444136]

66. McKinley L, Logar AJ, McAllister F, Zheng M, Steele C, Kolls JK. Regulatory T cells dampen pulmonary inflammation and lung injury in an animal model of pneumocystis pneumonia. $\mathbf{J}$ Immunol. 2006; 177:6215-6226. [PubMed: 17056551]

67. Hesse M, et al. The pathogenesis of schistosomiasis is controlled by cooperating IL-10-producing innate effector and regulatory T cells. J Immunol. 2004; 172:3157-3166. [PubMed: 14978122]

68. Guilliams M, et al. African trypanosomiasis: naturally occurring regulatory $\mathrm{T}$ cells favor trypanotolerance by limiting pathology associated with sustained type 1 inflammation. J Immunol. 2007; 179:2748-2757. [PubMed: 17709488]

69. Amante FH, et al. A role for natural regulatory $\mathrm{T}$ cells in the pathogenesis of experimental cerebral malaria. The American journal of pathology. 2007; 171:548-559. [PubMed: 17600128]

70. Steeg C, Adler G, Sparwasser T, Fleischer B, Jacobs T. Limited role of CD4+Foxp3+ regulatory T cells in the control of experimental cerebral malaria. J Immunol. 2009; 183:7014-7022. [PubMed: 19890049]

71. Carrigan SO, et al. Depletion of natural CD4+CD25+ T regulatory cells with anti-CD25 antibody does not change the course of Pseudomonas aeruginosa-induced acute lung infection in mice. Immunobiology. 2009; 214:211-222. [PubMed: 19215803]

72. Kotner J, Tarleton R. Endogenous CD4(+) CD25(+) regulatory T cells have a limited role in the control of Trypanosoma cruzi infection in mice. Infect Immun. 2007; 75:861-869. [PubMed: 17101658] 
73. Sales PA Jr, et al. The regulatory CD4+CD25+ T cells have a limited role on pathogenesis of infection with Trypanosoma cruzi. Microbes Infect. 2008; 10:680-688. [PubMed: 18485782]

74. Couper KN, Blount DG, de Souza JB, Suffia I, Belkaid Y, Riley EM. Incomplete depletion and rapid regeneration of Foxp3+ regulatory T cells following anti-CD25 treatment in malaria-infected mice. J Immunol. 2007; 178:4136-4146. [PubMed: 17371969]

75. Couper KN, et al. Anti-CD25 antibody-mediated depletion of effector T cell populations enhances susceptibility of mice to acute but not chronic Toxoplasma gondii infection. J Immunol. 2009; 182:3985-3994. [PubMed: 19299696]

76. Lund JM, Hsing L, Pham TT, Rudensky AY. Coordination of early protective immunity to viral infection by regulatory T cells. Science (New York, NY. 2008; 320:1220-1224.

77. Kim JM, Rasmussen JP, Rudensky AY. Regulatory T cells prevent catastrophic autoimmunity throughout the lifespan of mice. Nature immunology. 2007; 8:191-197. [PubMed: 17136045]

78. Fulton RB, Meyerholz DK, Varga SM. Foxp3+ CD4 Regulatory T Cells Limit Pulmonary Immunopathology by Modulating the CD8 T Cell Response during Respiratory Syncytial Virus Infection. J Immunol.

79. Pacholczyk R, Kern J, Singh N, Iwashima M, Kraj P, Ignatowicz L. Nonself-antigens are the cognate specificities of Foxp3+ regulatory T cells. Immunity. 2007; 27:493-504. [PubMed: 17869133]

80. Hsieh CS, Zheng Y, Liang Y, Fontenot JD, Rudensky AY. An intersection between the selfreactive regulatory and nonregulatory $T$ cell receptor repertoires. Nature immunology. 2006; 7:401-410. [PubMed: 16532000]

81. McKee AS, Pearce EJ. CD25+CD4+ cells contribute to Th2 polarization during helminth infection by suppressing Th1 response development. J Immunol. 2004; 173:1224-1231. [PubMed: 15240714]

82. Kinter AL, et al. CD25(+)CD4(+) regulatory T cells from the peripheral blood of asymptomatic $\mathrm{HIV}$-infected individuals regulate CD4(+) and CD8(+) HIV-specific T cell immune responses in vitro and are associated with favorable clinical markers of disease status. The Journal of experimental medicine. 2004; 200:331-343. [PubMed: 15280419]

83. Huang X, Zhu J, Yang Y. Protection against autoimmunity in nonlymphopenic hosts by CD4+ CD25+ regulatory T cells is antigen-specific and requires IL-10 and TGF-beta. J Immunol. 2005; 175:4283-4291. [PubMed: 16177068]

84. van Maren WW, Jacobs JF, de Vries IJ, Nierkens S, Adema GJ. Toll-like receptor signalling on Tregs: to suppress or not to suppress? Immunology. 2008; 124:445-452. [PubMed: 18540962]

85. Chen Q, Davidson TS, Huter EN, Shevach EM. Engagement of TLR2 does not reverse the suppressor function of mouse regulatory T cells, but promotes their survival. J Immunol. 2009; 183:4458-4466. [PubMed: 19748987]

86. Pasare C, Medzhitov R. Toll pathway-dependent blockade of CD4+CD25+ T cell-mediated suppression by dendritic cells. Science (New York, NY. 2003; 299:1033-1036.

87. Sather BD, et al. Altering the distribution of Foxp3(+) regulatory T cells results in tissue-specific inflammatory disease. The Journal of experimental medicine. 2007; 204:1335-1347. [PubMed: 17548521]

88. Schneider MA, Meingassner JG, Lipp M, Moore HD, Rot A. CCR7 is required for the in vivo function of CD4+ CD25+ regulatory T cells. The Journal of experimental medicine. 2007; 204:735-745. [PubMed: 17371928]

89. Wei S, Kryczek I, Zou W. Regulatory T-cell compartmentalization and trafficking. Blood. 2006; 108:426-431. [PubMed: 16537800]

90. Lehmann J, et al. Expression of the integrin alpha Ebeta 7 identifies unique subsets of CD25+ as well as CD25- regulatory T cells. Proc Natl Acad Sci U S A. 2002; 99:13031-13036. [PubMed: 12242333]

91. Huehn J, et al. Developmental stage, phenotype, and migration distinguish naive- and effector/ memory-like CD4+ regulatory T cells. The Journal of experimental medicine. 2004; 199:303-313. [PubMed: 14757740] 
92. Suffia I, Reckling SK, Salay G, Belkaid Y. A role for CD103 in the retention of CD4+CD25+ Treg and control of Leishmania major infection. J Immunol. 2005; 174:5444-5455. [PubMed: 15845457]

93. Yurchenko E, Tritt M, Hay V, Shevach EM, Belkaid Y, Piccirillo CA. CCR5-dependent homing of naturally occurring CD4+ regulatory T cells to sites of Leishmania major infection favors pathogen persistence. The Journal of experimental medicine. 2006; 203:2451-2460. [PubMed: 17015634]

94. Moreira AP, et al. CCR5-dependent regulatory T cell migration mediates fungal survival and severe immunosuppression. J Immunol. 2008; 180:3049-3056. [PubMed: 18292527]

95. Kroetz DN, Deepe GS Jr. CCR5 dictates the equilibrium of proinflammatory IL-17+ and regulatory Foxp3+ T cells in fungal infection. J Immunol. 184:5224-5231. [PubMed: 20335531] 